\title{
DE LA SMART CITY A LA SMART HUMAN CITY. INCLUSIÓN DIGITAL EN APLICACIONES
}

\section{FROM SMART CITIES TO SMART HUMAN CITIES: DIGITAL INCLUSION IN APP'S}

\author{
Eva María Olmedo Moreno \\ Adrián López Delgado \\ Universidad de Granada
}

\section{Resumen}

Las Smart Human cities, tienen como objetivos mejorar y facilitar la vida a los ciudadanos con la ayuda de las aplicaciones TICs (Apps, en adelante). El estudio que se presenta tiene como finalidad analizar las Apps, en cuanto a su accesibilidad y usabilidad para ciudadanos con disfuncionalidad visual, ya que esta dificultad es la que más influye en el uso eficaz y eficiente de las mismas. La muestra la constituyen 19 Apps cuyo criterios de selección son; los rankings de aplicaciones más empleadas en el año 2014 (google play, app store y iTunes Store) y aplicaciones desarrolladas por algunas Smart cities españolas (Gijón, Logroño, Madrid y Murcia). Para su análisis se construye una escala descriptiva en base a indicadores extraídos mediantes un proceso deductivo-inductivo. Un primer resultado es el "Sistema de indicadores para el análisis de la accesibilidad y usabilidad de las Apps" como modelo a aplicar.

De los cuatro entornos en los que se aglutinan las Apps más usadas, el social y más concretamente las aplicaciones de redes sociales, son las que más atiende a la accesibilidad; son muy demandadas y rentables para la industria de las telecomunicaciones. Sin embargo, el resto de aplicaciones son evaluadas como totalmente inaccesibles para estos usuarios.

Palabras clave: accesibilidad, aplicaciones informáticas; usabilidad, TIC, inclusión digital, evaluación de software, deficiencia visual, smart city.

\begin{abstract}
Smart cities have as goals to Improve and to make an easier life for their citizens throw ICT applications (Apps, hereinafter). The study aim to analyse Apps, abut its accessibility and usability for people with visual dysfunction, because this is the greatest disability with influence on the effective and efficient use of them. The sample constitutes 19 Apps whose selection criteria are; the rankings of most
\end{abstract}


used applications in 2014 (google play, app store and iTunes Store) and some applications developed by some Spanish Smart Cities (Gijon, Logroño, Madrid and Murcia). To analyse these data is made a descriptive scale based on indicators retrieved from a deductive-inductive process. First result is the "System of indicators for analysis accessibility and usability of Apps" as a model to apply.

On the four groups of most used Apps, social and social networking applications specifically, pay attention to better accessibility; they have a high demand by costumers and a high cost-profit rates to communications companies. However, other applications are evaluated as completely inaccessible to these special users.

Key words: accessibility, APP's, usability, ICT, digital inclusion, software evaluation, visual impairment, smart city.

\section{INTRODUCCIÓN Y ESTADO DE LA CUESTIÓN}

A lo largo de las últimas décadas, Internet se ha convertido en el primer medio para de comunicación. Sin embargo, a pesar de su extraordinario éxito, todavía hay muchos aspectos sin resolver. Como es la necesidad de avanzar en nuevas arquitecturas que puedan satisfacer la investigación y la sociedad (Domingue, 2011).

Las ciudades están en constante cambio, conforme avanzan los años se ha notado un aumento de la población urbana, es decir, cada vez más la población deja el ámbito rural para adentrarse en las comodidades que una ciudad puede aportar (Fundación Telefónica, 2011). Esta situación implica una sabia gestión de recursos, a través de las administraciones públicas y entidades empresariales involucradas.

La Comisión de Ciudades Digitales y del Conocimiento de CGLU (2012) explica que debido al desarrollo y al auge de las TIC, en los procesos de innovación y gestión, se ha generado un nuevo modelo de ciudad, donde estas se posicionan como medio esencial para hacer de las ciudades un lugar funcional, moderno y habitable. De la necesidad de modificar los modelos de organización de las ciudades surge el concepto anglosajón de Smart City; un concepto que está en constante cambio y revisión.

Las ciudades inteligentes están en constante crecimiento. Han pasado a ser una entidad propia, a valerse por ellas mismas. Éstas necesitan "(...)ser rentables, deben ser capaces de retener y atraer el talento, la capacidad de desarrollo, la cultura, el conocimiento, la innovación, la calidad, la economía, etc. Son como un organismo vivo 
que crece y aprende, que compite y produce. Una Smart City no es construir una ciudad totalmente tecnificada, con sistemas informáticos y tecnológicos complejos que anulen la voluntad y la participación humana hasta el punto de transformar a la población en meros consumidores-productores sin posibilidad de autogobierno o de toma de decisión alguna (...) No significa que la población realice todas sus gestiones online, (...) ni que todo esté abierto a cualquier desarrollo o implementación." (Colado, Gutiérrez, Vives y Valencia (2014: 2-3).

En cierto modo, a la hora de imaginar la ciudad del futuro, es normal que evoquen ideas del estilo de que con las tecnologías todo es más fácil y autodirigido, que todo está robotizado y automatizado, sin dar lugar a que los ciudadanos tomen acción en el día a día. Esto como vemos no es posible, ya que en la ciudad, los habitantes están en interacción con el contexto. Por tanto, el concepto de Smart City, según Colado et al. (2014) ha evolucionado en cuanto a cuatro aspectos imprescindibles:

$\checkmark$ Comunicaciones: Ser capaz de estar comunicados desde cualquier lugar y en todo momento es un hecho posible gracias a la llegada de Internet. Este aspecto se enlaza con el siguiente, ya que la comunicación entre usuarios implica ser un ente social.

$\checkmark$ Socialización: Con la llegada de Internet se inicia todo un sistema revolucionario de comunicación y socialización. La creación de espacios para este intercambio comunicativo e informativo se hace necesario, es por ello que se crean espacios en red, los cuales tienen como fin la construcción cooperativa: Blog, Wikipedia, Facebook, Linkedln, etc.

$\checkmark$ Medioambiente y Transparencia política: Ambos conceptos están muy relacionados entre sí, ya que con el avance de los años cada vez la sociedad está más sensibilizada y concienciada con la necesidad de protección y cuidado medioambiental, exigiendo a su vez a los poderes gubernamentales la creación de programas que palien la contaminación, la deforestación, el reciclaje, y en general aquellos problemas que atentan con el medioambiente.

En la Comisión de Ciudades Digitales y del Conocimiento de CGLU (2012) se aborda el término de ciudad inteligente como aquella en la que se consigue a través de la inversión en infraestructura y en sociedad, un desarrollo económico sostenible, una mejora de la calidad de vida y una gestión eficaz de los recursos naturales, y todo ello mediante la actuación de un gobierno participativo. La Smart City es, por tanto, el lugar idóneo para la innovación y la implantación de negocios e ideas, dando lugar al crecimiento económico y el desarrollo social. Donde los principales 
agentes implicados se encuentren interrelacionados entre sí, en cuanto a:

$\checkmark$ Economía (Smart Economy): Un modelo de ciudad competitivo, que busca mejorar a través de la innovación con mejoras económicas y productivas.

$\checkmark$ Gestión de Gobierno (Smart Governance): Agentes encargados de gestionar los servicios en diálogo con los ciudadanos.

$\checkmark$ Ciudadanía (Smart People and Smart Citizens): Destinatarios de las reformas tecnológicas de la ciudad.

$\checkmark$ Entorno (Smart Environment): Área en la que el habitante se desenvuelve e interacciona con los servicios que la ciudad proporciona.

$\checkmark$ Calidad de vida (Smart Living): Progreso de áreas como la educación, la cultura, la sanidad y el turismo.

$\checkmark$ Movilidad (Smart Mobility): Sistemas de transporte sostenibles y las infraestructuras TIC que facilitan la comunicación.

Son estos los agentes que según la literatura existente constituyen la base de una Smart City, sin embargo, a todos estos habría que añadir dos componentes esenciales:

$\checkmark$ Usabilidad: Capacidad que tienen los objetos o lugares de ser usado por cualquier usuario, independientemente de las capacidades del mismo.

$\checkmark$ Accesibilidad: Capacidad que tienen las Smart cities de proporcionar servicios adaptados a todos sus habitantes, en especial a aquellos que por circunstancias físicas, psíquicas, sensoriales o económicas se encuentran en desventaja con el resto de ciudadanos.

La falta de accesibilidad en entornos, productos y servicios, es lo que más discrimina (Alonso, 2007). El reivindicar una accesibilidad en el entorno ciudad no es un mero capricho al que se tiende en esta década, sino que es un derecho que se está negando a gran parte de la ciudadanía, y en especial al colectivo con discapacidad. A pesar de la existencia de acuerdos tan relevantes como los alcanzados la Convención Internacional sobre los Derechos de las personas con Discapacidad, de la que surge la Ley 26/2011, de 1 de agosto, con este mismo nombre. En ella se reflejan dos artículos que merecen destacarse, en cuanto al tema que nos atañe en este estudio:

$\checkmark$-El artículo 9, dedicado a la "accesibilidad", cuyo concepto tan amplio se refiere a componentes tales como edificios, vías 
públicas, transporte e instalaciones en general; servicios electrónicos y de comunicación.

$\checkmark$-El artículo 19, el "derecho a vivir de forma independiente y a ser incluido en la comunidad". Una parte muy importante si hablamos de ciudades accesibles, ya que para que el individuo se pueda desenvolver en la sociedad, es imprescindible que las instalaciones y los servicios comunitarios estén a disposición de éstos, atendiendo a las necesidades de los mismos.

Concretamente en el campo de las TIC, en la II Cumbre Mundial de Autoridades Locales sobre la Sociedad de la Información que se llevó a cabo en el año 2005 en Bilbao, donde participó la ONU, se trató la famosa "brecha digital" y la carencia de accesibilidad universal. En ella los gobiernos participantes se comprometieron a actuar en dicho ámbito, con la intención de avanzar y conseguir ciudades inclusivas. A grandes rasgos, algunos de los compromisos abordados se mueven en la línea de promover el software libre, creación de agenda digital local, movilizar recursos para la inclusión digital y desarrollar TIC inclusivas, entre otros (CGLU, 2012).

De la necesidad de desarrollar estrategias inclusivas para que todas las personas de un municipio se encuentren incluidos en el mismo, y evitar de esta manera diferencias entre personas, surge la idea de la Smart Human City. Este es un proyecto de ciudad más humano, que la Smart City, ya que atiende al ejercicio de derechos, y como principal receptor a los individuos. Para lo que se requiere de la estrecha colaboración entre administración pública y empresas privadas a la hora de la creación de material accesible para el sector con discapacidad, en un trabajo conjunto que genere la creación y desarrollo de los servicios básicos con aplicaciones TIC de forma accesible, sin necesidad de buscar alternativas (Álvarez, 2015).

Se hace necesario, por tanto, pensar más en el habitante; en el ciudadano. Creando entornos accesibles para todos y rompiendo así con la brecha digital que germina en nuestras nuevas ciudades inteligentes.

\section{PROBLEMA Y FINALIDAD DEL ESTUDIO}

Desde la aparición de los smartphones y tablets, se han creado cientos de aplicaciones móviles que facilitan el grado de desenvolvimiento en nuestra vida cotidiana dentro de la ciudad; desde conocer lugares de ocio, estado de las carreteras, interacciones sociales, marcadores de salud, entre otros. Sin lugar a dudas, abre las puertas a 
una nueva era, en la cual se nos facilita mucho la información, mejorando la autonomía de cada individuo. Pero, ¿̇qué es exactamente una "App"? Bien, el término de "app" proviene de la palabra aplicación, definida por Gil y Rodríguez-Porrero (2013) como una aplicación informática incluida en dispositivos móviles. Estas aplicaciones han sido diseñadas especialmente para su articulación en móviles y tablets, cuyo acceso es a través de una pantalla táctil. Dichas aplicaciones se pueden descargar, de manera gratuita o de pago, de sitios online gestionados por la compañía del dispositivo, aunque la plataforma más común y utilizada a nivel global es gestionada por la popular compañía Google, "Play Store".

A la hora de hablar de accesibilidad en una App, no sólo podemos referirnos a que el usuario pueda abrir o no la aplicación o pueda desenvolverse por el menú principal, sino a otros aspectos de la interfaz que pueden presentar barreras para algunos usuarios; la redacción de los mensajes, la organización en sí de la aplicación o los aspectos visuales como son el color, el contraste, entre otros. Todos estos elementos deben cuidarse por parte del diseñador, ya que son aspectos básicos que dificultan mucho la accesibilidad y usabilidad de la aplicación.

Una Smart citiy nos proporciona un amplio abanico de Apps para poder utilizar en el núcleo urbano, ya sean para la comunicación, el ocio, etc. A grandes rasgos, nos permiten estar en contacto directo con la ciudad y sus habitantes, pero para que ello ocurra es necesario que estas aplicaciones sean accesibles y usables, integrando de esta manera al mayor número de habitantes posible.

El estudio que se presenta tiene como finalidad analizar las aplicaciones facilitadoras de la vida urbana y socioeducativa, en cuanto a su accesibilidad y usabilidad para ciudadanos con disfuncionalidad visual, ya que esta es la que más influye en el uso eficaz y eficiente de las aplicaciones.

\section{POBLACIÓN Y MUESTRA}

Para abordar el problema planteado se ha realizado una selección de aplicaciones inteligentes enmarcadas en el contexto de las Smart cities, que tras un análisis descriptivo, se determinará si estas son accesibles y usables para el ciudadano con discapacidad visual. Esta discapacidad de la que hablamos puede aparecer por malformaciones, enfermedades o lesiones en el órgano de la vista, pudiéndose dar por origen hereditario -dominante, recesivo y ligado al sexo- o adquirido; en 
relación a la gravedad hablaremos de baja visión o de ceguera total (Lou, 2011).

La Organización Mundial de la Salud [OMS] (2014) en su nota descriptiva número 282 divide la capacidad de visión en 4 niveles: La visión normal, la discapacidad visual moderada, la discapacidad visual grave y la ceguera. Agrupando la antepenúltima y la penúltima en "baja visión", que junto al término de ceguera representan los casos de discapacidad visual. En el mundo encontramos 285 millones de personas que sufren discapacidad visual, 39 millones ciegas y 246 millones baja visión. A la luz de estos datos, un amplio sector de la población mundial padece esta discapacidad, siendo obligatorio atender y pensar en este colectivo a la hora de crear y diseñar espacios abiertos, edificios y tecnologías, entre las que se encuentran las Apps.

Para la selección de las aplicaciones se ha seguido el ranking publicado por google play (sistema operativo Android), app store (sistema operativo iOS) y iTunes Store (sistema operativo iOS) del año 2014 (Premium numbers, 2015; elPeriódico, 2015) de las Apps más descargadas en este año que se presentan en la figura 3:

Figura 3. Listado de las app's más utilizadas en 2014

\begin{tabular}{ccc}
\hline App Store (iOS) & Google Play (Android) & iTunes Store (iOS) \\
\hline Facebook Messenger & Duolingo & Facebook Messenger \\
\hline Snapchat & Facebook & WhatsApp Messenger \\
\hline YouTube & MyFitnessPal & Telegram Messenger \\
\hline Facebook & Netflix & Facebook \\
\hline Instagram & Pandora & YouTube \\
\hline Pandora Radio & NFL Mobile & Google Maps \\
\hline Google Maps & Flipagram & Instagram \\
\hline Flipagram & TripAdvisor & Spotify Music \\
\hline Spotify Music & Candy Crush Saga & Shazam \\
\hline 2048 & & Wallapop \\
\hline
\end{tabular}


De esos rankings se han seleccionado las aplicaciones relacionadas con el tema principal del estudio y se han añadido otra serie de Apps típicas de las ciudades inteligentes españolas (Gijón, Logroño y Madrid y Murcia). La muestra final la componen las 19 Apps potencialmente más implicadas en el desarrollo de una Smart city. Estas han sido agrupadas según entornos de acción:

El entorno educativo o profesional es un ámbito por el que todos los usuarios de una ciudad se mueven en algún momento de sus vidas, de manera continua o temporal. En éste, el participante toma parte activa de su aprendizaje o desarrollo profesional, siendo necesario de herramientas o recursos para este proceso. Hace unas décadas, las bibliotecas, enciclopedias, diccionarios, de manera física, era el recurso por excelencia para dicho ámbito, actualmente una Tablet o un móvil y conexión a la red sustituyen cientos de los recursos anteriores. En este entorno se incluyen aquellas aplicaciones que tienen como principal fin ayudar al usuario en su ámbito profesional o educativo, como son: Google, Dropbox y Duolingo.

$\checkmark$ Google Chrome. Un navegador web en nuestro móvil es fundamental para la búsqueda y acceso a la información. El Google Chrome es el buscador web más utilizado, quizás por disponer de diversas herramientas dentro del navegador, desde la navegación en modo incógnito, visor de PDF y geolocalización, hasta la personalización de la aplicación en sí y la traducción de enlaces. Sin lugar a dudas, es un buscador bastante completo cuya interfaz es intuitiva y sencilla.

$\checkmark$ Dropbox. Este servicio proporciona de manera gratuita unas gigas de memoria en la nube, que posibilitaran al usuario a tener sus documentos, fotos y demás, sincronizados. Permitiendo compartir carpetas con otros usuarios y facilitando el intercambio de documentos y la elaboración conjunta de archivos.

$\checkmark$ Duolingo. Con la intención de facilitar formación en idiomas de manera gratuita, dispone de cursos de idiomas como el español, francés, inglés, portugués, alemán, entre otros. Está organizado de tal forma que mediante avances con los cursos que ofrece, es posible la traducción de textos, partiendo del trabajo cooperativo.

El entorno social es el ámbito por el que la persona se mueve durante más tiempo a lo largo de su vida. Éste innegablemente tiene un componente afectivo y emocional, compuesto por un círculo de relaciones que cada persona va formando a lo largo del tiempo. Por tanto, en el entorno social se incluirán aquellas aplicaciones que ayudan al usuario a desenvolverse con más facilidad en sociedad, en relación al 
desarrollo interpersonal de éste. Se engloban aquellas aplicaciones que posibilitan la organización del ocio y tiempo libre, y que brindan la posibilidad de interaccionar entre los integrantes de la urbe, como son: Facebook, Twitter, Youtube, Whatsapp, Wallapop, App ciudad, EsAccesible, Smartappcity, CiudadGijón, Fever y Google Wallet o Apple Pay.

$\checkmark$ Facebook, como red social, permite estar en contacto con usuarios amigos, compartir fotos, comentarios y noticia. Permite conocer que hacen o por donde se mueven nuestra red de contactos, siendo posible interactuar y compartir con ellos todo aquello que consideramos interesante. Crear tu propia red de contactos, "siguiendo" a diversos usuarios, es su mayor potencialidad en el desarrollo personal y profesional, ya que en esta pueden estar integradas empresas, amigos, asociaciones, entre otros.

$\checkmark$ Youtube. Permite compartir vídeos en la red con millones de usuarios, como también ser receptor de contenido multimedia que crean otros usuarios particulares o empresas de producción. Desde el año 2005 es un nuevo medio revolucionario para la transmisión cultural.

$\checkmark$ Whatsapp. Esta aplicación de mensajería instantánea te permite enviar y recibir mensajes, imágenes, audios, vídeos, ubicaciones, entre otros. Configurar grupos y mantener conversaciones abiertas entre sus miembros es uno de sus grandes potencialidades.

$\checkmark$ Wallapop. Espacio en línea que pone en contacto a vendedores y compradores de tu zona, a través del servicio de geolocalización que permite buscar y poner en venta productos tanto nuevos como de segunda mano. Te da la posibilidad de comunicarte con compradores, calificarlos y acomodar la compra-venta según tu disponibilidad.

$\checkmark$ App ciudad. Con la intención de querer integrar todos los servicios de la ciudad en una aplicación móvil se ha creado App ciudad. En ella se integran servicios desde el tiempo de la ciudad y eventos, hasta rutas y mapas de la ciudad. Esta aplicación dispone de dos novedosos apartados, como es el "viaja y trabaja" que te da la posibilidad de visitar otras ciudades y ver ofertas de trabajo temporales en ella. Es una aplicación en desarrollo y adaptada a la ciudad que la demanda como es el caso de Murcia, Granada, Barcelona, Madrid y Valencia.

$\checkmark$ EsAccesible. Evalúa desde el punto de vista del usuario la accesibilidad física de los lugares que se encuentran en su entorno: parques, bares, aparcamientos, etc. El ciudadano tienen a su disposición 4 descriptores para valorar los lugares, si 
el sitio es accesible al 100\% se le da una puntuación alta. Esta valoración es recogida por google maps, donde se marcan y el usuario puede encontrar aquellos lugares accesibles.

$\checkmark$ Smartappcity. Se ha creado con la intención de aunar todos los servicios que ofrece una ciudad, aportando información a tiempo real de las prestaciones de la misma. La idea de colaboración propuesta facilita mucho más el acceso a los servicios, sin necesidad de acudir a diversas aplicaciones para estar al tanto de lo que ofrece la ciudad. Está en desarrollo y actualmente podemos encontrar ciudades como Logroño, Jaén y Antequera, que ya cuenta con esta App.

$\checkmark$ CuidaGijón (Gijón). El encontrar desperfectos en nuestra zona residencial $O$ en nuestra ciudad es un hecho que se da habitualmente. El Ayuntamiento de Gijón ha creado esta aplicación con la intención de tener conectados a sus ciudadanos y hacerlos formar parte activa en el mantenimiento y cuidado de su localidad, alcanzando un mayor nivel de eficiencia y ahorro.

$\checkmark$ Fever. Es común movernos por los lugares más populares y seguir consejos que te dan compañeros o amigos, según los gustos y preferencias de cada individuo, para así proporcionarte los planes más idóneos a realizar con antelación. Está disponible para ciudades españolas como Madrid, Barcelona, Valencia, Málaga y Sevilla, pero desde que esta empezó se han ido incorporando nuevas ciudades.

$\checkmark$ Google Wallet. Es un aplicación de pago móvil con la que es posible realizar pagos en establecimientos, pagar deudas a amigos, o hacer pagos en línea. Para ello, es necesario la tecnología NFC (Near Field Communication), que actualmente los Smartphones y algunas tablets de última generación lo llevan incorporado en su interior. Se estima que es cuestión de tiempo que éste sea el sistema de pago habitual en las ciudades inteligentes.

El entorno salud y deporte es uno de los que más auge han tenido en los últimos años. La población cada vez es más consciente de su físico y los efectos que tienen en éste el deporte, por ello son más los que se animan a practicarlo. Engloba aquellas aplicaciones que impulsan la práctica del deporte, la mejora del bienestar físico y la salud del ciudadano: Endomondo y MyFitnessPal.

$\checkmark$ Endomondo. Deporte al aire libre, entrenamiento autónomo y localización GPS definen perfectamente a esta novedosa aplicación que acompaña al usuario en su entrenamiento en la naturaleza, ya sea ciclismo, carrera o senderismo. Asimismo, 
posibilita dejar y recibir comentarios a usuarios amigos en su función de recogida y almacenamiento de todos los entrenamientos te permite competir con otros usuarios.

$\checkmark$ MyFitnessPal. Ha sido creada para llevar un control de la alimentación y de las calorías que se ingieren a lo largo del día. La idea de la misma nace por la creencia de que llevando un control de lo que se come se consigue una equilibrio de salud y alimentación. Permite introducir todos los alimentos que vas a comer, disponiendo de lector de códigos de barras, para así conocer el tipo de alimento con los nutrientes y calorías que lo integran, y generar un progreso propio aumentando la motivación ya que permite estar conectado en grupos.

$\checkmark$ Entorno de movilidad. No se podría considerar entorno como tal, pero la demanda del ciudadano en este sector es tanta, que se hace necesario establecer un ámbito donde englobar aquellas aplicaciones que el usuario necesita para organizar sus itinerarios de viaje, buscar medios de transporte, alquiler de vehículos, entre otros. Por lo tanto, en este entorno se desarrollaran aquellas aplicaciones que facilitan al usuario los procesos de organización de viajes: TripAdvisor, Blablacar, Madrid Metro/Bus/Cercanías y Google maps.

$\checkmark$ TripAdvisor. Este buscador web permite la reserva y organización de viajes de manera online. Presenta una serie de destinos en la que viajeros han comentado expresando sus experiencias sobre el producto. Gracias a este feedback el usuario que va a reservar un destino, puede obtener diversas opciones, y permite buscar hoteles, restaurantes y lugares de ocio en el destino elegido.

$\checkmark$ Blablacar. Plataforma online que pone en contacto a conductores y pasajeros es la tendencia actual para los viajes a corta y larga distancia, que tiene como objetivo la división de gastos y el cuidado del medio ambiente. Cuenta con un servicio de feedback, mediante el cual valoras a los usuarios con los que has viajado, como también es posible que te valoren a ti mismo, de esta forma se busca asegurar honestidad y fiabilidad entre los usuarios.

$\checkmark$ Madrid Metro/Bus/Cercanías (Madrid). La gran urbe dispone de diversos medios de transportes para ser utilizados en ella como autobuses, metro y cercanías. Esta aplicación te proporciona toda la información necesaria para poder moverte por Madrid, te organiza el destino explicándote que transbordos tienes que hacer y el tiempo que durará el viaje.

$\checkmark$ Google Maps. Aplicación móvil que permite la visualización de mapas de google, siendo posible desplazarte sobre éste para buscar sitios en concreto. El servicio GPS permite encontrar lugares y además ofrecerte rutas en coche, a pie o en transporte 
público, para llegar al destino deseado y si se prefiere evitando zonas colapsadas. Asimismo, google maps te ayuda a buscar establecimientos públicos y privados como restaurantes, bancos, aparcamientos cercanos al lugar donde te sitúas. Siendo una guía personal en la ciudad.

\section{ANÁLISIS DE DATOS}

En este apartado se van a recoger los análisis de las aplicaciones móviles seleccionadas, las cuales se encuentran organizadas en los entornos, previamente descritos. Cada una de las aplicaciones es sometida a una evaluación a través de un sistema de indicadores creado de forma deductiva e inductiva, para el este estudio, y que por sí mismo forma parte de los propios resultados del mismo.

\subsection{Sistema de indicadores}

Este sistema con ocho indicadores es la base para el análisis de la accesibilidad y usabilidad de cada App seleccionada en cada entorno. Cada uno de estos indicadores se describe a continuación en su correspondiente ficha técnica.

\section{Primer Indicador}

\section{Nombre del Indicador. Siglas.}

Descripción de las imágenes. Desclmgn.

\section{Objetivo del Indicador.}

Comprobar si la interfaz de las aplicaciones inteligentes de las Smart cities permite la descripción de imágenes, gráficos, colores..., mediante voz o texto. Destinado al usuario con baja visión, daltonismo y ceguera.

\section{Justificación del Indicador.}

Las imágenes, los esquemas, los gráficos, los colores son indispensables, no se puede concebir información sin ir complementado de estos recursos, pues facilita mucho más la comprensión y la claridad en la exposición. Por ello, es necesario que el colectivo con discapacidad visual pueda acceder sin problema alguno a ello, y centrándonos en las aplicaciones inteligentes, se hace necesario que esta sea capaz de descodificar la información en texto escrito y sonoro, para conseguir una comunicación accesible. 


\section{Definición y conceptualización.}

La descodificación de gráficos, imágenes, esquemas, colores..., en texto escrito o sonoro refiere a la posibilidad en la que la interfaz de la aplicación permite su interpretación por el usuario con discapacidad visual.

\section{Método de medición.}

Opción dual: Si lo permite la interfaz (valor 1) o No lo permite la interfaz (0).

\section{Variables.}

Imágenes, gráficos, colores, situaciones, etc.

\section{Limitaciones del Indicador.}

Hay un gran número de aplicaciones inteligentes, por lo tanto es muy difícil encontrar aplicaciones accesibles; que den la posibilidad a descodificar imágenes, colores, esquemas, situaciones, etc.

\section{Fuente de datos.}

Análisis descriptivo de aplicaciones inteligentes de Smart cities, extraídas éstas de empresas tecnológicas.

\section{Nombre del Indicador. Siglas.}

\section{Segundo Indicador}

Contenido multimedia agrandable. ContMultiAgra.

\section{Objetivo del Indicador.}

Comprobar si la interfaz de las aplicaciones inteligentes de las Smart cities permiten agrandar el contenido multimedia. Destinado en principio al usuario con baja visión.

\section{Justificación del Indicador.}

Debido a la necesidad de acercar las Smart cities a toda la población, es necesario que las aplicaciones que nos aportan información acerca del medio, y nos hacen interactuar con el mismo, sea clarificativa y sencilla para que toda la población pueda acceder a ella. En el caso del individuo con discapacidad visual, el contenido que presentan estas aplicaciones debe tener la capacidad de aumentar su tamaño, para que así cualquier persona con problemas de visión pueda acceder a dicha información; más concretamente el contenido multimedia, ya que el colectivo con discapacidad visual padece carencias perceptivas. 


\section{Definición y conceptualización.}

La posibilidad de aumentar el contenido multimedia refiere a la hora de acceder a información en un soporte, en la medida en que esta tiene la capacidad de ampliar su tamaño.

\section{Método de medición.}

Opción dual: Si lo permite la interfaz (valor 1) o No lo permite la interfaz (0).

\section{Variables.}

El contenido (Imágenes, gráficos, etc).

\section{Limitaciones del Indicador.}

Hay un gran número de aplicaciones inteligentes, por lo tanto es muy difícil encontrar aplicaciones accesibles; que permitan aumentar el tamaño del contenido multimedia para facilitar la usabilidad de todos sus usurarios.

\section{Fuente de datos.}

Análisis descriptivo de aplicaciones inteligentes de Smart cities, extraídas éstas de empresas tecnológicas.

\section{Nombre del Indicador. Siglas.}

\section{Tercer Indicador}

Contraste, brillo y color. ContrstBrillColr

\section{Objetivo del Indicador.}

Evaluar en qué medida la interfaz de una app propia de Smart city permite modificar el contraste, brillo y color de la pantalla para facilitar la lectura de la pantalla al usuario con baja visión.

\section{Justificación del Indicador.}

El contraste, brillo y color son tres aspectos de la pantalla de cualquier terminal que dificultan bastante la lectura para el usuario con baja visión. Ya sea el bajo contraste, la mala combinación de colores, el brillo...

Que el usuario pueda acceder a los ajustes de la aplicación y modificar estos aspectos básicos a su gusto harán que la aplicación sea accesible a un mayor número de individuos. 


\section{Definición y conceptualización.}

Contraste, brillo y color son aspectos visuales del terminal que dificultan el acceso a la información para el usuario con baja visión. El control de la configuración de la aplicación permitirá al usuario modificar a su manera estos aspectos visuales.

\section{Método de medición.}

Opción dual: Si lo permite la interfaz (valor 1) o No lo permite la interfaz (0).

\section{Variables.}

Contraste, brillo y color.

\section{Limitaciones del Indicador.}

Es posible que aspectos como brillo y contraste no se considere necesario incluirse dentro de la aplicación en sí, ya que el propio terminal tecnológico permite modificar estos dos aspectos al gusto del usuario.

\section{Fuente de datos.}

Análisis descriptivo de aplicaciones inteligentes de Smart cities, extraídas éstas de empresas tecnológicas.

\section{Nombre del Indicador. Siglas.}

\section{Cuarto Indicador}

Señales auditivas. SeñAudi.

\section{Objetivo del Indicador.}

Comprobar si las aplicaciones disponen de señales auditivas que guíen el proceso en la aplicación. Destinado en principio para el usuario con ceguera.

\section{Justificación del Indicador.}

La necesidad de navegar por la aplicación se hace cada vez más evidente para obtener información, ya que éstas no son de una sola ventana o pantalla. Por ello, es necesario que este tipo de navegación sea intuitiva y sencilla, y además de que disponga de sonido para orientar el proceso del usuario.

\section{Definición y conceptualización.}

Las aplicaciones inteligentes deberán facilitar la navegación al usuario con discapacidad visual mediante señales auditivas.

\section{Método de medición.}

Opción dual: Si lo permite la interfaz (valor 1) o No lo permite la interfaz (0). 


\section{Variables.}

Etiquetas auditivas y guías auditivas.

\section{Limitaciones del Indicador.}

Gran número de aplicaciones, siendo posible que algunas se escapen del análisis.

Dificultad de encontrar aplicaciones que automaticen estos aspectos.

\section{Fuente de datos.}

Análisis descriptivo de aplicaciones inteligentes de Smart cities, extraídas éstas de empresas tecnológicas.

\section{Nombre del Indicador. Siglas.}

\section{Quinto Indicador}

Superficie táctil. SuperTctil

\section{Objetivo del Indicador.}

Comprobar si las teclas táctiles que aparecen en las ventanas de las aplicaciones tienen un mínimo de $9 \mathrm{~mm}$ de ancho y largo.

\section{Justificación del Indicador.}

La falta de visión del colectivo afectado por ceguera y baja visión hace necesaria estandarizar los controles de la aplicación, para conseguir que estos usuarios puedan interactuar sin problema con ella.

\section{Definición y conceptualización.}

El tamaño de los controles es una barrera para el acceso a la aplicación. Estandarizar un tamaño mínimo de $9 \mathrm{~mm}$ tanto de ancho como de largo va a facilitar mucho más el acceso a usuarios con discapacidad visual.

\section{Método de medición.}

Opción dual: Si lo permite la interfaz (valor 1) o No lo permite la interfaz (0).

\section{Variables.}

Tamaño controles.

\section{Limitaciones del Indicador.}

Es posible que el tamaño de los controles varíe según el medio tecnológico usado. 


\section{Fuente de datos.}

Análisis descriptivo de aplicaciones inteligentes de Smart cities, extraídas éstas de empresas tecnológicas.

\section{Nombre del Indicador. Siglas.}

\section{Sexto Indicador}

Controles personalizables. CntrIPrsnble

\section{Objetivo del Indicador.}

Evaluar en qué medida la configuración de la aplicación permite cambiar los controles que dan acceso a las distintas ventanas de la misma. Ya sea cambio de tamaño o color.

\section{Justificación del Indicador.}

Con problemas como la baja visión y el daltonismo surge la necesidad de modificar aspectos de la interfaz para mejorar el proceso del usuario. Un cambio de color y tamaño puede significar un mundo para este colectivo.

\section{Definición y conceptualización.}

Los controles de acceso a las distintas ventanas de la aplicación deben poder ser personalizables, para que el usuario independientemente de su dificultad pueda modificar aquello que crea conveniente.

\section{Método de medición.}

Opción dual: Si lo permite la interfaz (valor 1) o No lo permite la interfaz (0).

\section{Variables.}

Controles.

\section{Limitaciones del Indicador.}

Son aspectos muy particulares de una interfaz y por lo tanto es difícil que una aplicación por si misma pueda aportar esto.

\section{Fuente de datos.}

Análisis descriptivo de aplicaciones inteligentes de Smart cities, extraídas éstas de empresas tecnológicas. 


\section{Nombre del Indicador. Siglas.}

\section{Séptimo Indicador}

Texto agrandable. TxtoAgrnble

\section{Objetivo del Indicador.}

Evaluar si la interfaz de la aplicación propia de Smart city permite que el texto que expone se pueda modificar de tamaño.

\section{Justificación del Indicador.}

La baja visión provoca grandes problemas de agudeza visual, siendo necesario utilizar aparatos secundarios como lupas para la lectura del contenido escrito.

Las aplicaciones inteligentes para que sean accesibles deben permitir que el contenido que se muestre pueda ser modificado de tamaño.

\section{Definición y conceptualización.}

El usuario con baja visión tiene problemas en la lectura de la información escrita, ya sea por el tamaño o por la claridad. Por ello, es fundamental que esta información se pueda agrandar para que así el usuario con baja visión pueda acceder de manera más sencilla a dicho contenido.

\section{Método de medición.}

Opción dual: Si lo permite la interfaz (valor 1) o No lo permite la interfaz (0).

\section{Variables.}

Texto

\section{Limitaciones del Indicador.}

Tener que reducir texto para que al agrandarlo no ocupe toda la pantalla y provoque fatiga en el usuario.

\section{Fuente de datos.}

Análisis descriptivo de aplicaciones inteligentes de Smart cities, extraídas éstas de empresas tecnológicas.

\section{Octavo Indicador}

\section{Nombre del Indicador. Siglas.}

Mensajes claros. MensjClaro. 


\section{Objetivo del Indicador.}

Ver en qué medida las aplicaciones son accesibles con la información que estas aportan, en relación al ser clarificativos y concisos. Destinadas en principio para el usuario con baja visión.

\section{Justificación del Indicador.}

Dentro de cualquier aplicación inteligente se nos va a presentar distinto tipo de información, desde las normas de uso y condiciones, hasta la información que nos aporte acerca del tiempo que va a hacer la semana próxima. Esta información para la población discapacitada debe ser concisa y clarificativa, ya que los restos visuales de los que disponga el usuario están muy limitados, y una reducción del texto va ayudar a que el usuario se pueda mover con mayor facilidad por la aplicación.

\section{Definición y conceptualización.}

El usuario con baja visión requiere que la información que este recibe a través de sus ojos sea lo más breve y claro posible. Por ello es indispensable reducir los textos y las palabras, para que de un solo golpe de visión el usuario pueda recibir la información que necesita.

\section{Método de medición.}

Opción dual: Si lo permite la interfaz (valor 1) o No lo permite la interfaz (0).

\section{Variables.}

Texto, frases, palabras.

\section{Limitaciones del Indicador.}

Es difícil y complicado hallar aplicaciones accesibles en general, y más difícil aún con aspectos característicos como éste.

\section{Fuente de datos.}

Análisis descriptivo de aplicaciones inteligentes de Smart cities, extraídas éstas de empresas tecnológicas.

\section{RESULTADOS}

En base al estudio realizado, hemos obtenido como primer resultado un "Sistema de indicadores para el análisis de la accesibilidad y usabilidad de las Apps". Este sistema ha sido comprobado como eficaz para las 19 aplicaciones seleccionadas. 
Se ha obtenido cuatro categorías de Apps en cuanto a la relación del ciudadano con las mismas:

$\checkmark$ App accesible en sí. Aquella aplicación cuya interfaz permite adaptar los elementos de la aplicación haciendo de ella un espacio accesible para el usuario que la requiere.

$\checkmark$ App con herramienta de accesibilidad del terminal. Aplicación que por sí misma no dispone de elementos accesibles para que el usuario que la precise pueda acceder a ella, y por ello requiere de herramientas especiales para adaptar y transmitir el contenido (TalkBack, por ejemplo).

$\checkmark$ App gemela. Aplicación que se crea en paralelo a la original con la intención de suplir las carencias en accesibilidad de ésta.

$\checkmark$ Aplicación sin base específica en accesibilidad y usabilidad. Aquella aplicación cuya interfaz no permite adaptar los elementos de la aplicación haciendo de ella un espacio inaccesible para el usuario que la requiere.

Del análisis por entornos de cada una de las Apps seleccionadas, y aplicando la escala descriptiva en base a los indicadores expuestos, se obtienen los siguientes resultados:

\section{Entorno "Educación"}

En este entorno se analiza el famoso buscador de Google, la aplicación nube de Dropbox y el curso online de idiomas de Duolingo.

En lo que se refiere a descripción de imágenes, ninguno de ellos aportan información complementaria, simplemente se adjunta el contenido. Algo parecido pasa a la hora de agrandar el contenido multimedia, aunque aquí destaca Google Chrome, quizás por su función de navegabilidad por la pantalla táctil, que es la que permite con un simple toque de dedo agrandar al gusto el contenido.

Para el usuario con discapacidad visual, las señales auditivas pueden marcar la diferencia entre saber desenvolverse por la aplicación o no, de ahí su importancia, al igual que la modificación de los controles, que permitan cambiar color y tamaño según la necesidad. Sin embargo ninguna de las anteriores aplicaciones permite este apoyo. Sin embargo, la superficie táctil mínima, si es un aspecto incluido por todas.

El texto agrandable es otro de los elementos fundamentales e indispensables para que accedan el mayor número de usuarios posibles. En este apartado ocurre lo mismo que con el contenido multimedia. Pues Google Chrome debido a su función de navegabilidad lo permite, sin embargo las otras dos aplicaciones no lo facilitan. 
Por último, encontramos algo común en las tres aplicaciones a analizar del entorno educación, y es el indicador de mensajes claros, pues toda la información expuesta en ella es concisa y clarificativa.

\section{Entorno "Social"}

La descripción de imágenes, en la cual se engloban también los gráficos, los colores y los vídeos, encontramos como Youtube se desmarca, proporcionando subtítulos a sus vídeos. Sin embargo, aunque en esta aplicación ese factor está disponible, son pocos los canales que proporcionan contenido con posibilidad de añadir subtítulos. Es cierto que una descripción de imágenes ayuda a los invidentes a comprender el contenido de la misma, sin embargo, es difícil pensar cómo se podría conseguir que ésta pudiera describir todo el contenido que se expone en las redes sociales.

Centrándonos en la posibilidad de agrandar el contenido multimedia, encontramos como destaca en parte Smartapp city (Logroño.es), permitiendo agrandar el tamaño de los mapas para la geolocalización, además de modificar de entrada el nivel de zoom del mismo, sin necesidad de ir agrandando digitalmente la pantalla táctil. También destaca aquí CuidaGijón, que permite agrandar los controles e imágenes de la interfaz, aunque en ocasiones estos se desmarquen, consiguiendo to do lo contrario, necesita mejorar.

El contraste, brillo y color es un aspecto muy importante a tener en cuenta. En este sentido, Whatsapp no permite modificar muchos aspectos, aunque sí el color del fondo a nuestro gusto, que ayudará al usuario a controlar el contraste con el texto escrito.

La posibilidad de personalizar los controles es algo que desde el primer momento no se pensó que alguna aplicación lo posibilitara. Sin embargo, la aplicación Smartapp city (Logroño.es), al acceder a la pantalla inicial por primera vez, te da a elegir entre dos tipos de menús, uno "general" que contiene imágenes en los iconos con su rótulo en blanco, o una versión "accesible" en la cual el menú es más intuitivo y sencillo, con texto blanco sobre un fondo rojo redondeado. Sin lugar a dudas, es una buena práctica, aunque se debería de permitir modificar colores, tamaño de icono y organización, para así mejorar aún más la experiencia del usuario.

En lo referente a la posibilidad de agrandar el texto, encontramos que Twitter y Whatsapp nos da la posibilidad de modificar la fuente al tamaño preferido, algo normal, ya que trabaja principalmente con ese tipo de contenido. Youtube, lo único que permite en este caso es agrandar el tamaño de los subtítulos, dejando un poco de lado los títulos y comentarios de los vídeos colgados en red. 
Cabe destacar que Whatsapp permite trascribir la propia voz en texto, además de posibilitar enviar audios con nuestra voz a otros usuarios, por lo tanto, a la hora de comunicarnos con nuestros contactos, no se tendrá ningún problema.

\section{Entorno "Salud y deportes"}

En la aplicación "Endomondo", a la hora de su contenido multimedia, es de destacar que permite que los mapas de la geolocalización se puedan agrandar a gusto. Por lo demás, se consideran aplicaciones poco accesibles para el colectivo referido.

\section{Entorno "Movilidad"}

Una gran cantidad de aplicaciones presentan imágenes, gráficos y demás para ayudar al usuario en el mejor entendimiento de la misma, o simplemente para acompañar la información escrita que se expone en ella. Por tanto, es importante que el usuario con problemas de visión pueda acceder a ésta, y para ello se requiere una descripción del contenido.

Los mapas con las líneas de metro son un ejemplo claro de lo que nos puede facilitar un simple mapa esquemático. Sin embargo, el usuario con daltonismo o cualquier otro problema de visión se encuentra aquí con una gran barrera. En la aplicación "Madrid Metro/Bus/Cercanías" encontramos como se presentan estos mapas, un gran revoltijo de líneas de colores, y en cada extremo su número de la línea. Totalmente inaccesible para este colectivo, siendo necesario requerir de otras aplicaciones como "ONCE - CIDAT Metro", elaborada hace 3 años por la ONCE, que incluye todas las redes de metro de España de manera accesible.

Un aspecto novedoso encontrado en la aplicación de Google Maps, y no encontrado en las demás analizadas, son las señales auditivas, ya que la interfaz de la aplicación te facilita la interacción con la aplicación a través de audio, sin embargo, únicamente a la hora de utilizar el servicio GPS, queriendo ir de un punto hacia otro.

TripAdvisor, en cuanto a ampliar el contenido, se desmarca permitiendo agrandar las imágenes que expone en su plataforma. Sin embargo, los gráficos no disponen de esta opción.

Tras el análisis de las 19 aplicaciones inteligentes elegidas con el sistema de indicadores diseñado, encontramos algunos aspectos accesibles que se repiten en todas. Éstos son la superficie táctil mínima de $9 \mathrm{~mm}$, y la claridad expositiva en la información expuesta. Es algo positivo, claro está, pero el resto de aspectos no alcanzan niveles mínimos. 


\section{DISCUSIÓN Y CONCLUSIONES}

Desde el tejido empresarial e incluso el social, se tiende a pensar que la inversión en la accesibilidad de las aplicaciones inteligentes no va a ser rentable, como bien explica Alonso (2007), el proceso de supresión de barreras implican intervenciones bastantes complejas y que en muchas ocasiones generan un alto coste, al ir dirigidas únicamente a un porcentaje pequeño de población. Dicho porcentaje podría no ser tan reducido, atendiendo a los datos expuestos en este estudio, con 290 millones de ciudadanos afectados por una disfunción visual.

El entorno social, quizás es uno de los más comerciales, en el cual las empresas tecnológicas se involucran para proporcionar a la población lo que esta demanda. En cierto modo, en los resultados, se puede apreciar este matiz, ya que ha sido el entorno en cuyas aplicaciones tienen más factores accesibles, destacando la posibilidad de agrandar los textos y el contenido multimedia en la mayoría de interfaces.

Sin embargo, en términos generales, aplicaciones tan conocidas como las extraídas de los rankings citados, en el análisis son inaccesibles para un usuario que quiere simplemente salir a dar un paseo (google map) o para aquel que quiere medir su alimentación en calorías (MyFitnessPal). Son datos escandalizadores, pues nos hacen pensar que no son facilitadoras del día a día para la población, sino parte de la denominada brecha digital.

La otra realidad encontrada en este estudio, son las Apps creadas desde las Smart cities, que en su conjunto son más accesibles. Lo que denota que para las administraciones públicas, la accesibilidad si es un factor considerado, aunque aún deben seguir progresando hacia una accesibilidad universal; en la que se incluyen las aplicaciones inteligentes accesibles como demanda ciudadana. Cabe destacar que esta necesidad latente a nivel social ha dado lugar a la creación de modelos de negociar que giran alrededor de Internet, dando a la sociedad lo que va requiriendo, ya sean aplicaciones, plataformas, etc. De esta forma se logrará el paso de Smart cities a Smart Human cities.

\section{REFERENCIAS BIBLIOGRÁFICAS}

Alonso, F. (2007). Algo más que suprimir barreras: conceptos y argumentos para una accesibilidad universal [Versión electrónica]. Trans. Revista de traductología, 2, 15-30. 
Álvarez, M. J. (2015, abril). Smart Human City - Hacia una ciudad inteligente para todas las personas. Trabajo presentado en el I congreso de ciudades inteligentes, Madrid. Recuperado de http://es.slideshare.net/regalado3/estilo-apa-sexta-edicin

Colado, S., Gutiérrez, A., Vives, C. J \& Valencia, E. (2014). Smart city. Hacia la gestión inteligente. Barcelona: Marcombo.

C.G.L.U. (2012). Smart city studies: estudio internacional sobre la situación de las TIC, la innovación y el Conocimiento en las ciudades. Bilbao. Recuperado el 23 Enero, 2012, de http://www.socinfo.es/contenido/seminarios/1404smartcities6/04BilbaoSmartcitiesstudy es2012.pdf

Dominque, J. (2011). The future Internet: Achievements and Technological Promises. Springer.

Fundación Telefónica (2011). Smart cities: Un primer paso hacia la internet de las cosas. Consultado en http://smartcity-telefonica.com/pageflip/informe_anual.pdf (20/4/2014).

Gil, S. \& Rodríguez-Porrero, C. (2013). Cómo hacer "apps" accesibles". Infórmate sobre... Madrid: CEAPAT-IMSERSO. Recuperado el 21 Enero, 2015,

de http://www.ceapat.es/InterPresent1/groups/imserso/documents/binario/appsacces ibles.pdf

Ley $26 / 2011$, de 1 de agosto, de adaptación normativa a la convención internacional sobre los derechos de las personas con discapacidad. Boletín Oficial del Estado, España, 2 de agosto de 2011.

Lou, M. A. (2011). Atención a las necesidades educativas específicas: educación secundaria. Madrid: Ediciones Pirámide.

O.N.U. (2006). Convención Internacional sobre los Derechos de las Personas con Discapacidad.

Organización Mundial de la Salud. (2014). Ceguera y discapacidad visual. Recuperado el 11 Febrero, 2015 de http://www.who.int/mediacentre/factsheets/fs282/es/

Premium numbers. (2015). Las 10 apps más descargadas en 2014 (iOs y Android). Recuperado el 08 Abril, 2015 de http://www.premiumnumbers.es/blog/index.php/2014/12/29/apps-masdescargadas-en-2014-ios-android/ 


\section{Sobre los autores:}

\section{Eva María Olmedo Moreno}

Es Doctora en Pedagogía por la Universidad de Granada y Profesora Titular en el Departamento de Métodos de Investigación y Diagnóstico en Educación de la Universidad de Granada, donde imparte la materia troncal de Métodos de Investigación Educativa. Su principal línea de investigación versa sobre "Estrategias de Aprendizaje y el desarrollo de la Cultura de la Hiper-globalización-Smart Cities", tema sobre el que ha dirigido y dirige varias Tesis Doctorales. En la actualidad participa en varios Programas de Doctorado y Masters, nacionales e internacionales, de reconocido prestigio por agencias como ANECA.

\section{Adrián López Delgado}

Realiza sus estudios de Grado en la Facultad de Ciencias de la Educación de la Universidad de Murcia. Es Magister en Intervención Psicopedagógica por la Universidad de Granada. Actualmente se encuentra realizando su trabajo de plan de investigación en accesibilidad y usabilidad de aplicaciones para el contexto social, educativo y de ocio-tiempo libre de las actuales ciudades inteligentes.

\section{Para citar este artículo}

Olmedo Moreno, E. V. \& López Delgado, A. (2015). De la Smart City a la Smart Human City. Inclusión digital en aplicaciones. Revista Fuentes, 17 (Diciembre), 41-65. [Fecha de consulta: dd/mm/aa]. doi: doi: http://dx.doi.org/10.12795/revistafuentes.2015.117.02. 